\title{
As questões étnico-raciais na obra Memórias de um Sargento de Milícias
}

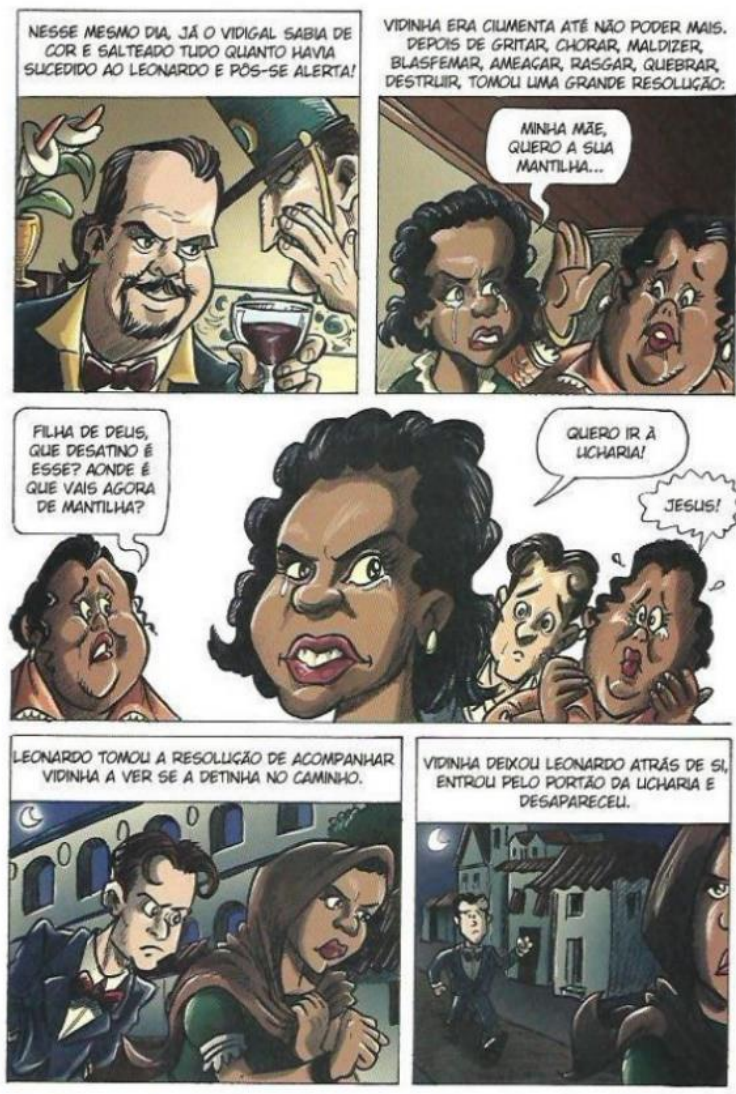

RESUMO: Neste trabalho, temos como preocupação abordar a presença das questões étnico-raciais que atravessam vários momentos da obra "Memórias de um Sargento de Milícias" de Manuel Antônio de Almeida. O romance de costumes escrito de 1852 a 1853, na forma de folhetim em um jornal de circulação, tem uma trama que enfoca as classes populares e seus cotidianos e não os grupos burgueses como até então eram realizados os romances de costumes da época. A partir da leitura da obra selecionamos alguns trechos e abordamos como estão estabelecidas as relações étnico-raciais no livro. Além disso, a leitura do trabalho com enfoque nas relações étnico-raciais contribui para o alargamento da discussão no campo do Pensamento Social Brasileiro; e para compreendermos melhor os conflitos raciais que estão nas raízes históricas da formação da sociedade brasileira

PALAVRAS-CHAVES: Pensamento Social; Antropologia; Étnico-raciais.

1 Mestra em Relações Étnico-raciais/CEFET-RJ, Doutoranda em Ciências Socais/PPGCIS Pontifícia Universidade Católica do Rio de Janeiro. E-mail: luanebentosantos@gmail.com 


\section{Introdução}

Neste trabalho, temos como preocupação abordar a presença das questões étnico-raciais que atravessam vários momentos da obra "Memórias de um Sargento de Milícias" de Manuel Antônio de Almeida. O romance de costumes escrito de 1852 a 1853, na forma de folhetim em um jornal de circulação da época, tem uma trama que enfoca as classes populares e seus cotidianos e não os grupos burgueses como até então eram realizados os romances de costumes da época. De acordo com alguns autores (CÂNDIDO, 1993; OTSUKA, 2008) uma inovação para a maneira como eram escritos os romances da época que sempre centravam o modelo de vida burguês. Nesse sentido, a obra rompe com um panorama estabelecido e apresenta os invisíveis que almejam se tornarem visíveis a partir da ascensão social e econômica. Ademais faz uma certeira aposta neles ao colocá-los no lugar de personagens principais.

No campo das Ciências Sociais muitos trabalhos se voltaram para a análise da referida obra, podemos citar aqui: CÂNDIDO, 1993; OTSUKA, 2008, Azevedo, Costa Souza e Mochel, 2018. No entanto, as questões de grupos étnico-raciais como negros e mestiços escravizados, ciganos e populações indígenas ainda merecem mais atenção porque estão presentes no decorre da leitura do texto. Ao longo da leitura há trechos em que aparecem e são descritos rituais religiosos e festivos de grupos ciganos, negros e caboclos (que podemos ler também como indígenas ou povos originários). Estes trechos são carregados de conotações estigmatizadas que revelam um modo de pensar sobre grupos subalternizados e que são recorrentes até os dias atuais na sociedade brasileira. Para nós a obra apresenta questões ainda atuais sobre a sociedade brasileira no que se refere as relações raciais e que não revelam apenas o pensamento da época, mas um pensamento ainda presente em nosso cotidiano. Mesmo após os inúmeros avanços políticos alcançados no Brasil após a III Conferência Mundial contra o Racismo, Discriminação Racial, Xenofobia e Intolerâncias Correlatas, realizada de 31 de agosto a 7 de setembro de 2001, em Durban, África do Sul. Nesta conferência o Estado brasileiro se comprometeu a promover uma série de políticas de ações afirmativas com os grupos étnico-raciais historicamente discriminados ${ }^{2}$. Contudo, nas relações cotidianas muito dos conflitos continuam marcados por preconceitos ligados as percepções de raça e etnia, o que demonstra assim a complexidade de nossas relações sociais.

Dito isto, procuramos no trabalho refletir como essas questões étnicoraciais estão colocadas no romance. Para isso, na primeira parte analisamos alguns trechos em que personagens ciganos (as), negros (as) e mestiços (as) são narrados em suas ações e em outros momentos representados. $\mathrm{Na}$ segunda parte refletimos como as mulheres negras, mestiças e ciganas são representadas e coisificadas na obra. Posteriormente, fazemos as considerações finais.

2 Para mais esclarecimentos ver LIMA, Márcia. Desigualdades raciais e políticas públicas: ações afirmativas e governo Lula. In: Novos Estudos - CEBRAP, 2010, n. 87, pp. 77-95. 


\title{
Os indesejáveis: negros (as) escravizados, ciganos e caboclos
}

A obra de Manoel Antonio de Almeida situa-se no período anterior a República e aonde a organização social, econômica e moral do país estava alicerçada no trabalho dos escravizados. Este ponto é crucial para entendermos a obra do autor. Por isso, o romance já inicia, no primeiro capítulo com o trecho "Era no tempo do rei" e no decorrer da leitura a instituição da escravidão será componente de várias cenas. Neste sentido, a escravidão não é invisível na obra do autor, pelo contrário estar lá impregnada nas passagens do livro, nas cenas da vida cotidiana. Vejamos no capítulo II um trecho em que a instituição da escravidão aparece para tratar do tema da intriga, popularmente conhecida como fofoca. "Espiar a vida alheia, inquirir dos escravos o que se passava no interior das casas, era naquele tempo coisa tão comum e enraizada nos costumes, que ainda hoje, depois de passados tantos anos restam grandes vestígios desse belo hábito (ALMEIDA, 1988, pp.13-14).

Apesar do autor não tratar diretamente da escravidão na obra os grupos escravizados aparecem em vários momentos para compor a cena ${ }^{3}$ ou talvez para salientar a existência dessa instituição social que atravessou mais de trezentos anos da história do Brasil.

No capítulo IV, intitulado Fortuna, o autor narra as tentativas amorosas mal sucedidas de Leonardo Pataca (pai) do protagonista do romance. Para isso, ele apresenta a aproximação de Leonardo em rituais de natureza afro-indígena, cujo principal objetivo era conquistar o amor de uma cigana ${ }^{4}$ a quem se apaixonou. Leonardo recorre a figura de um caboclo, retratado na obra de modo irônico, oculto, como feioso, suspeito, perigoso e nada higiênico.

\begin{abstract}
Lá para as bandas do mangue da Cidade Nova havia, ao pé de um charco, uma casa coberta de palha da mais feia aparência, cuja frente suja e testada enlameada bem denotavam que dentro o asseio não era muito grande. Compunha-se ela de uma pequena sala e um quarto; toda a mobília eram dois ou três assentos de pau, que tinha muitos empregos; era mesa de jantar, cama, guarda-roupa e prateleira. Quase sempre estava essa casa fechada, o que rodeava de um certo mistério. Esta sinistra morada era habitada por uma personagem talhada pelo molde mais detestável; era um caboclo velho, de cara hedionda e imunda e coberto de farrapos. Entretanto, para admiração do leitor, fique-se sabendo que este homem tinha por ofício dar fortuna [...] e não era só a gente do povo que dava crédito às feitiçarias; conta-se que muitas pessoas da alta sociedade de
\end{abstract}

3 Destacamos dois trechos em que Almeida (19880 trata de vários momentos do cotidiano e insere os escravizados como elementos pertencentes a cena " $D$. Maria estava já pronta e os esperava com algumas outras pessoas com quem também tratará ir de companhia, em nenhum momento puseram-se a caminho. Formavam todos um grande rancho acompanhado por um número não pequeno de negras e negrinhas escravas e crias de D. maria, que levavam cestos com comidas e esteiras ( $p$. 61)"Quando passava a Via-Sacra e que se acendia a lâmpada do oratório, o pai de família que morava ali pelas vizinhanças tomava o capote, chama toda gente de casa, filhos, filhas, escravos e crias ( $p$. 72)"

4 A cigana como muitos personagens da obra não tem nome 
então iam às vezes comprar venturas e felicidades pelo cômodo preço da prática de algumas imoralidades e superstições (ALMEIDA, 1988, p. 19).

Como podemos ver o autor tem uma preocupação em descrever as feições do Velho Caboclo como horrendas e de causar medo através das palavras hedionda e imunda, além disso descreve também as condições de pobreza a que estar inserido quando nos diz que o sujeito estava coberto de farrapos. Chama atenção que o Velho Caboclo como muitos personagens não tem nome, mas diferente de outros sujeitos subordinados o autor se ateve em delinear seus aspectos físicos, principalmente os do rosto (da face). De acordo com Le Breton (2004), a face ocupa um importante papel na constituição de pessoa e identidade.

Com o passar do tempo, a face torna-se um lugar de reconhecimento mútuo, nós portamos mãos e rosto nus e ofereceremos aos outros as marcas e traços que nos identificam. Através de nosso rosto somos reconhecidos, chamados, julgados, nos atribuem um sexo, uma idade, uma cor de pele. Somos amados, desprezados ou anonimizados e afogados na indiferença da multidão. Conhecer o outro implica em the permitir ver e compreender uma face nutrida de sentidos e valores e, desse modo, espelhar na sua própria face um lugar igualmente pleno de significação e interesses [...] Nas nossas sociedades individualistas, 0 valor da face se impõe exatamente aonde 0 reconhecimento de si ou dos outros se faz a partir da individualidade e não sobre as formas de pertencimento a um grupo ou ao lugar que ocupamos em uma linhagem. A singularidade da face responde a singularidade do homem. Dito de outro modo, a singularidade da face corresponde à mesma singularidade do artista, dos valores de sua existência, responsável e autônoma por suas escolhas. Nesse registro não existe mais o homem e a mulher do "nós mesmos", como nas sociedades tradicionais, mas do "pessoalmente/ para $\mathrm{mim} / \mathrm{eu}$ ". Para que um indivíduo adote sentido cultural e socialmente, é preciso que exista um meio para o corpo se distinguir com tal força, com tamanha variação para significar, sem ambiguidade, a diferença de um indivíduo ao outro. É preciso que o corpo se transforme em um limite de si para com os outros e com o mundo externo. Trata-se do corpo como fronteira da identidade. É preciso também que o rosto se torne o território do corpo no qual se inscreve essa distinção individual. Nenhum espaço do corpo é mais apropriado para marcar a singularidade do indivíduo e fazê-lo também socialmente (p.1).

Os aspectos ressaltados pelo autor acerca da face do Velho Caboclo (que pode ser lido como um sujeito mestiço ou indígena) estão alinhados as perspectivas de sua época, sem dúvidas, no entanto, eles reafirmam para o leitor a necessidade desse sujeito ser punido e banido pela força da lei através da figura do Vidigal. $\mathrm{Na}$ atualidade muitos casos de intolerância religiosa são alimentados por descrições próximas as realizadas pelo autor, especialmente as intolerâncias praticadas contra as religiões de matrizes africanas. Um caso que ganhou destaque na mídia e na esfera jurídica foi a intolerância religiosa praticada por membros da Igreja universal do Reino de Deus/IURD contra a sacerdotisa Mãe Gilda na Bahia. Vejam como essas ideias se mantém até os dias atuais e causam efeitos violentos como na passagem citada do livro neste trabalho: 


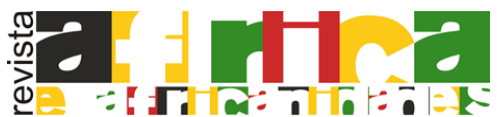

Revista África e Africanidades - Ano XIII - n. 34, maio. 2020 - ISSN 1983-2354 www. africaeafricanidades.com.br

A revista Veja publicou matéria em 1992, em que aparecia uma foto de Mãe Gilda, trajada com roupas de sacerdotisa, tendo aos seus pés uma oferenda como forma de solicitar aos orixás que atendessem às súplicas daquele momento. A lurd publicou essa fotografia no jornal Folha Universal, em outubro de 1999, associada a uma agressiva e comprometedora reportagem sobre charlatanismo, sob o título: "Macumbeiros charlatões lesam o bolso e a vida dos clientes". A matéria afirmava estar crescendo no País um "mercado de enganação". Nesta reportagem, a foto da Mãe Gilda, aparece com uma tarja preta nos olhos (TEMPO E PRESENÇA DIGITAL, S.I,)

Precisamos dizer que longe de fazer uma análise anacrônica da obra, na realidade, procuramos demonstrar como essas situações trazidas pelo autor atravessam o tempo e continuam presentes na sociedade atual.

Nesse mesmo capítulo o autor também se preocupa em descrever a presença dos grupos Ciganos no Brasil. Segundo Almeida:

Com os emigrados de Portugal veio também para o Brasil a praga dos Ciganos. Gente ociosa e de poucos escrúpulos, ganharam ele aqui reputação bem merecida dos mais refinados velhacos: ninguém que tivesse juízo se metia com eles em negócio, porque tinha certeza de levar carolo. A poesia de seus costumes e de suas crenças, de que muito se fala, deixaram-na da outra banda do oceano; para cá só trouxeram maus hábito, esperteza e velhacaria (1988, p.24).

Finalmente no capítulo IX, chamado de O - Arranjai-me - do compadre, a instituição econômica da escravidão aparece de modo mais direto para retratar a trajetória de sobrevivência e os primeiros ofícios do padrinho de nosso protagonista.

Quando passou de menino a rapaz e chegou a saber barbear e sangrar sofrivelmente, foi obrigado a manter-se à sua custa e a pagar a morada com os ganchos que fazia, porque o produto do mais trabalho pertencia ainda ao mestre. Sujeitou-se a isso. Porém queriam ainda mais: exigiam-se que continuasse a empregar-se no serviço doméstico. Lavrou-Ihe então n'alma um arrepio de dignidade: já era oficial, e não queria rebaixar o seu ofício. Virou mareta; fez-se duro e safou-se de casa sem escrúpulos ou remorsos [...] Viu-se na rua, sem saber para onde ir, tendo por única fortuna uma bacia de barbear embaixo do braço, um par de navalhas e outro de lancetas na algibeira [...] pobre rapaz estava em apertos [...] No largo do Paço um marujo que estava sentado em uma pedra junto ao mar chamou-o para que lhe fizesse a barba: mãos à obra que já naquele dia não morria de fome. Todo barbeiro é tagarela, e principalmente quando tem pouco que fazer, começou, portanto, a puxar conversa com o freguês. Foi a sua salvação. O navio que o marujo pertencia viaja para a Costa e ocupava-se no comércio de negros; era um dos comboios que traziam fornecimento para o Valongo, e estava pronto a largar [...] No dia seguinte saiu o nosso homem pela barra fora: a fortuna tinha-lhe dado o meio, cumpria sabê-lo aproveitar; de oficial de barbeiro dava um salto mortal a médico de navio negreiro (ALMEIDA, 1988, pp. 30-31).

Notamos pela passagem como a questão da escravização dos grupos africanos, trazidos forçadamente para serem explorados nas colônias, fazia parte do cotidiano da sociedade a ponto de não se levantado pelo autor nenhum questionamento sobre sua existência ou então o mesmo deixar escapar no trecho algum grau de ironia ou crítica a esse holocausto humano. 
Pelo contrário, a escravidão com seus navios negreiros era a base da economia, de modo, que empregava trabalhadores e como no caso do compadre ainda lhes dava outra profissão. A escravidão estava arraigada na sociedade colonial e imperial.

Em relação a escravidão na obra de Almeida (IBIDEM), os autores Azevedo, Costa Souza e Mochel (2018) argumentam o seguinte:

Entendemos que o período narrado pelo autor compreendia uma realidade de mais de 300 (trezentos) anos de escravidão negra, assim a escravidão era uma instituição, um sistema de produção legitimado e justificado por meio da religião, "um Catolicismo formalista, numa poderosa junção de interesses religiosos, políticos e comerciais numa ligadura que era ao mesmo tempo econômica, política e social e que tendia a mexer-se como uma totalidade", fazendo com que "fosse aceito como normal pela maior parte de nossas elites" (DAMATTA, 2010, p. 70). O que justifica a não evocação dos escravizados diretamente na narrativa do autor [...] à incorporação da escravidão no senso comum, como algo dado, e, portanto, sem necessidade de nomeação porque já faz parte da narrativa (p.73).

Nesse sentido, a escravidão fazia parte da atmosfera social como dissemos e alicerçava o sistema econômico e político da sociedade. Assim seria impossível não transparece no romance do autor.

Outro aspecto importante que deve ser mencionado aqui é que a trama escrita por Almeida (1988) centraliza o trabalho livre. OTSUKA (2008) sobre isso nos alerta:

Como se sabe, o foco fechado na esfera dos "homens livres pobres" deixa de fora do romance as duas camadas principais da sociedade, entre as quais se estabeleciam as relações decisivas do ponto de vista da organização econômica: a esfera do mando (a elite proprietária) e a do trabalho (a massa de escravos). Abarcando na representação somente uma camada social restrita, e não o conjunto da sociedade, as Memórias fornecem uma imagem aparentemente amena do Rio de Janeiro do período joanino (p. 1).

Ao final da análise literária de Memórias de um Sargento de Milicias o pesquisador Antônio Cândido (1993) observa "Lá não se trabalha, não se passa necessidade, tudo se remedeia. Na sociedade parasitária e indolente, que era a dos homens livres do Brasil de então, haveria muito disto, graças à brutalidade do trabalho escravo, que o autor elide junto com outras formas de violência (pp. 53-54.)".

Outro ponto que merece atenção e envolvem as relações étnico-raciais na obra são as considerações a respeito de mulheres negras e mestiças. Sobre isso discorreremos na próxima parte.

\section{Mulheres negras e mestiças}

O modo como o autor descreve mulheres negras e mestiças também nos trouxe algumas inquietações ao longo da leitura. De acordo com Antônio Cândido, as pessoas de cor só aparecem na obra de modo decorativo 
Havia, porém, um elemento mais antigo e importante para o quotidiano, que formava a maior parte da população e sem o qual não se vivia: os escravos. ora, como nota Mário de Andrade, não há 'gente de cor", no livro -, salvo as baianas da procissão dos Ourives, mero elemento decorativo, e as crias da casa de Dona Maria, mencionadas de passagem para enquadrar o Mestre de Reza (p.50).

Acreditamos que as mulheres de grupos étnicos subordinados aparecem, ora de modo decorativo como nos trechos destacados por Bandeira, ora no lugar de sexualizadas, voluptuosas e como aqueles que violam as regras de bons costumes. Na passagem sobre as baianas, no capítulo XVIII, vemos uma caracterização de suas roupagens que segundo o autor não deveriam ser adotadas pelo restante das mulheres pois levaria a perdição e pecado.

Todos conhecem o modo por que se vestem as negras na Bahia; é um dos modos de trajar mais bonitos que temos visto,, não aconselhamos porém que ninguém o adote; um país em que todas as mulheres usassem desse traje, especialmente se fosse desses abençoados em que elas são alvas e formosas, seria uma terra de perdição e de pecados. Procuremos descrevê-lo. As chamadas Baianas não usavam de vestido; traziam somente umas poucas de saias presas à cintura e que chegavam pouco abaixo do meio da perna, todas elas ornadas de magníficas rendas; da cintura para cima apenas traziam uma finíssima camisa, cuja gola e mangas eram também ornadas de renda; ao pescoço punham um cordão de ouro e um colar de corais (p. 53)

Pela descrição do autor notamos que a indumentária das Baianas era muito bonita, contudo, não deveriam ser utilizadas pelo restante das mulheres, já que personificavam a passagem para uma vida pecaminosa, de desordem e perdição. As Baianas representavam as mulheres que ocupavam a rua, ou seja, as mulheres da rua. Da Matta (1986) comenta:

Assim, se a mulher é da rua, ela deve ser vista e tratada de um modo. Trata-se, para ser mais preciso, das chamadas mulheres da 'vida', pois rua e vida formam uma equação importante no nosso sistema de valores. (DAMATTA, 1986, p. 30).

Azevedo, Costa Souza e Mochel (2018, p. 67) assinalam sobre a forma como o autor diferencia a personagens Luisinha e Vidinha e destacam os elementos de classe e raça presentes nessa diferenciação "Cabe, desde já, ressaltar que Luisinha é descrita como branca pelo livro e Vidinha como negra [...] A afilhada de Dona Maria, Luisinha, adequava-se ao modelo de passividade e submissão, já Vidinha era passional e tinha uma postura ativa diante da sociedade."

Essas caracterizações das mulheres negras na obra são presentes até os dias atuais e podem ser traduzidas em ditados populares como: branca para casar, mulata para fornicar e negra para trabalhar. A respeitos dos efeitos da escravização nas práticas sociais Custódio (2005, p.39) salienta:

Deve-se acrescentar que os efeitos devastadores da escravidão foram diferentes nos casos dos homens e no caso das mulheres. A demonstração de poder sobre a coisa (escravo) se dava de maneira diferente nas relações senhor-escravo, senhora-escravo, senhor-escrava, senhora-escrava. Segundo Giacomini (1982) as relações entre senhor-escravo e senhora escrava se realizaram de modo a exercer o poder pela força, já nas relações entre senhor 
escrava, esse poder geralmente era exercido através da sexualidade. As relações entre senhora-escrava eram baseadas na violência como forma de punição contra a escrava por "seduzir" o senhor, ou seja, eram baseadas na agressão por ciúmes ou simples maldade. A escrava além do trabalho deveria ainda oferecer o corpo tanto como ama de leite ou como amante.

\section{Considerações Finais}

As tentativas de análise do trabalho foram de apontar onde na obra Memórias de um Sargento de Milícias de Manoel Antônio Almeida apareciam as questões étnico-raciais ou seus vultos negros e negras escravizados, ciganos (as) e caboclos. Procuramos demonstrar como as perspectivas abordadas no livro são presentes até os dias atuais e com a literatura para além de produzir uma ficção está impregnada de pensamentos políticos e sociais que informam sobre o seu tempo. Vimos como as passagens e poucas descrições dos sujeitos negros, mestiços e ciganos aparecem de modos similares em nossa contemporaneidade. $\mathrm{Na}$ realidade, são realimentadas constantemente por práticas hoje vistas como preconceituosas e discriminatórias. Contudo, no período de escrita da obra faziam parte do senso coletivo e moral da sociedade brasileira.

Este trabalho ajudou-nos a problematizar as raízes históricas e as bases literárias que alimentam as percepções sobre grupos subordinados. A partir dele fomos às literaturas que abordaram a situação dos povos escravizados $e$ trabalhadores livres no século XVIII e XIX. Pensamos que para nossa área de pesquisa as relações étnico-raciais contribuem solidamente.

Para finalizar, a obra ainda pode ser lida por outras vias pois apresenta um cenário das classes populares não trabalhado em obras do mesmo período.

\section{Referências}

ALENCASTRO, L. F. de. O trato dos viventes: formação do Brasil no Atlântico Sul, séculos XVI e XVII. São Paulo, Companhia das Letras, 2000.

Proletários e escravos: imigrantes portugueses e cativos africanos no Rio de Janeiro, 1850-1872. Novos estudos CEBRAP, n. 21, São Paulo, julho 1988, pp. 30-56.

ALMEIDA, Manoel Antônio de. Memórias de um Sargento de Milícias. São Paulo, Editora Ática, 1988.

AZEVEDO, Gustavo Cravo de; SOUZA, Joyce Gonçalves Restier da Costa; MOCHEL, Juliana Sousa de Araújo. Memórias de um sargento de milícias: abordando negritude, gênero e acesso à escola no livro de Manoel Antônio de Almeida. In: Perspectiva Sociológica, ‥ 22, 2ำ sem. 2018, p. 60-80

CÂNDIDO, Antônio. Dialética da malandragem. In: $O$ discurso e a cidade. São Paulo, Duas Cidades, pp. 19-54.

CUSTÓDIO, Meliza da Silva. Mulher negra: da inserção na história a inserção na propaganda. In: Revista de Iniciação Científica da FFC, v. 5, n. 1/2/3, p. 37-49, 2005 
DAMATTA, Roberto. A Casa \& a rua. In: O que faz o Brasil, Brasil? Rio de Janeiro: Rocco, 1986.

GIACOMINI S, Maria. Mulher e escrava, uma introdução histórica ao estudo da mulher negra no Brasil. Local: Vozes, 1988.

LE BRETON, David, ANTROPOLOGIA DA FACE: alguns fragmentos. In: REVISTA POLÍTICA \& TRABALHO, n. 47, 2018.

OTSUKA, E. T. Espírito rixoso: para uma reinterpretação das Memórias de um sargento de milícias. Revista do IEB, n. 44, São Paulo, 2007, pp. 105-124.

A questão do trabalho nas Memórias de um sargento de milícias. In: $X I$ Congresso Internacional da ABRALIC Tessituras, Interações, Convergência, 13 a 17 de jul. ano 2008, USP - São Paulo, Brasil. 